\title{
Bowel obstruction and cecal volvulus as a complication of laparoscopic adjustable gastric banding: A case report
}

\author{
Paul Levy, Lauren E. Smith* \\ Grandview Medical Center, Department of Surgery, Dayton, OH, United States
}

Received: September 7, 2017

Accepted: October 27, 2017

Online Published: November 2, 2017

DOI: $10.5430 /$ css.v3n4p15

URL: https://doi.org/10.5430/css.v3n4p15

\begin{abstract}
Obesity is a common condition in westernized countries and it is increasing in prevalence in both pediatric and adult populations. Morbidity associated with severe obesity can be life threatening. Surgical intervention has demonstrated efficacy at reduction of morbidity and mortality resulting from obesity. The laparoscopic adjustable gastric banding (LAGB) is a well-known bariatric procedure which has been popular for its minimally invasive approach. Several early and late complications from this procedure have been reported in the literature. The most common complications involve slippage of the band and local inflammatory processes related to the subcutaneous port site. This case report describes a 59-year-old female who developed a bowel obstruction secondary to a cecal volvulus caused by adhesions to her gastric band connecting tube. This is another example of one of the many growing, yet unusual complications associated with the LABG.
\end{abstract}

Key Words: Obesity, Bariatric surgery, Laparoscopic adjustable gastric banding, Large bowel obstruction, Cecal volvulus

\section{INTRODUCTION}

Westernized nations have witnessed a marked increase in the prevalence of obesity over the past twenty years. Consequently, obesity and obesity-related morbidity have become major problems for patients and health care providers worldwide. ${ }^{[1]}$ From 1991 to 2000, the incidence of morbid obesity rose $133 \%$ in the United States. A review of the 2000 NHIS reveals that there is 5,324,123, or $2.8 \%$, of the American population who are eligible for obesity surgery. ${ }^{[2]}$ With such a rapid velocity of increasing obesity, it is reasonable to assume that an even greater population qualify for obesity surgery today. Multiple studies identify obesity as a contributing or causative factor in a myriad diseases including but not limited to: heart disease, hypertension, obstructive sleep apnea, asthma, diabetes, gallbladder disease, hyperlipidemia and increased rates of multiple types of cancer. ${ }^{[3]}$

There are also psychosocial and socioeconomic consequences for the obese patient. ${ }^{[4]}$ Many treatments may be prescribed to the obese patient; these often include change in diet, exercise, medical and other behavioral modifications. Sadly, these treatments often are not successful for long-term weight loss. Surgery offers patients an effective option for obesity treatment. According to Ballantyne, surgery is in fact the most effective means to achieve long-term weight loss in the morbidly obese. ${ }^{[5]}$

One such surgical intervention for obesity is the laparoscopic adjustable gastric band (LAGB) which was introduced in

\footnotetext{
* Correspondence: Lauren E. Smith; Email: laur.smithDO@ gmail.com; Address: Grandview Medical Center, Department of Surgery, 405 W Grand Ave, Dayton, OH 45405, United States.
} 
the 1990s. This procedure gained widespread popularity in part due to its minimally invasive approach, reversibility, and low reported incidence of complications. However, over time, many complications have come to light regarding the LAGB. ${ }^{[6]}$ The overall complication rate with the LAGB in a series reported by Susmallian was $25.8 \%$. Other reports detailed complications specific to the band itself such as band slippage and erosion of the band into the stomach. ${ }^{[7]}$ Other studies have reported novel late complications such as recurrent small bowel obstruction caused by the connecting tube of a LAGB ${ }^{[8-11]}$ and cecal volvulus caused by the band tube. ${ }^{[12-14]}$

We report a case of cecal volvulus caused by adhesion of the cecum to the gastric band tubing. While cecal volvulus has been reported in previous case studies, we are not aware of any reported cases caused by adhesion of the cecum directly to the gastric band tube.

\section{CASE REPORT}

A 59-year-old female presented to the emergency department with abdominal pain that had been present for approximately six hours. The patient stated that she had gone to exercise at the gym in the morning and was feeling well at that time. She came home after that and was sitting on the couch when she experienced sharp epigastric pain that radiated to her left flank and back. The patient denied any nausea, vomiting, or diarrhea. She did have a bowel movement prior to the start of her pain that was normal in caliber and consistency. She denied obstipation. She did have a history of placement of a LAGB nine months prior to this episode. Her past medical history was significant for hypertension, hyperlipidemia, and morbid obesity. Within the past nine months since her LAGB placement, she reported a 100-pound weight loss. Besides the LAGB, her surgical history included cholecystectomy, appendectomy, exploratory laparotomy, hysterectomy, and pelvic surgery for a prolapsed bladder.

On physical exam, she was afebrile and normotensive. There was a palpable fullness in the left and right upper quadrants of her abdomen. She was also tender to palpation. Her gastric band subcutaneous port was palpated in its proper location with no gross evidence for local inflammatory reaction. Laboratory data demonstrated a white blood cell count of 11,300 with no evidence of left shift or bands. Her hemoglobin was 15.3. Renal function, electrolytes, and urinalysis were all within normal ranges. A KUB was obtained and demonstrated evidence of gaseous distension of the bowels and stomach with horizontal position of the gastric band which was suspicious for a band slip (see Figure 1). The patient was taken to fluoroscopy for a gastrograffin swallow. The contrast did not move into the stomach at all which was felt to be diagnostic of a slipped band. The decision was made to take the patient to the operating room for a diagnostic laparoscopy with removal of her gastric band.

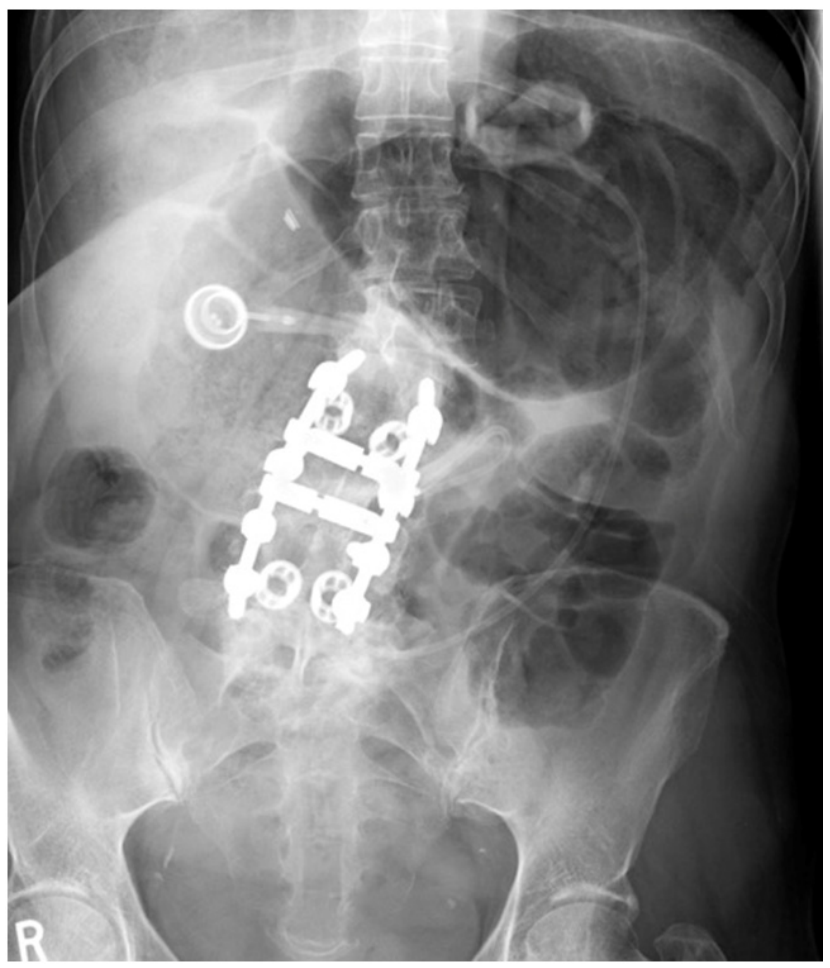

Figure 1. The patient's KUB demonstrates the gastric band is in a horizontal position and the left upper quadrant is filled with gas distended bowels

This was suspicious for gastric band slippage

We started her operation with the placement of a supraumbilical laparoscopy port and established pneumoperitoneum in the usual fashion. Upon insertion of the laparoscope, we were able to visualize a large loop of dilated colon on the left side of the abdomen which completely obscured the view of the stomach. After multiple attempts to manipulate the bowel, we were still unable to visualize her band and elected to convert to an open procedure.

A standard midline laparotomy was undertaken with lysis of some adhesions to allow access to the intraperitoneal viscera. Once the gastric band could be visualized, it was noted to be in the proper position with no evidence for slippage. Further examination of the abdomen revealed adherence of the patient's cecum to the gastric band tubing. The cecum was noted to be rotated about its axis in a counterclockwise direction thus creating a volvulus. The adhesions to the tube were lysed sharply and the rotation of the cecum was reduced back to the correct anatomic position in the right lower quadrant. After the cecum was returned to the correct anatomic position, we excised the involved portion of tubing 
and reconnected the tube to the gastric band. The cecum was noted to be markedly distended but all tissue was viable. Due to the massive dilation, a purse string suture was placed on the anterior portion of the cecal bulb and an enterotomy was made where suction was placed into the lumen of the cecum to perform decompression. A decision was made not to excise the involved segment and cecopexy was not performed. The abdomen was then irrigated and closed in a standard multilayer fashion.

The patient tolerated the procedure well. She was admitted to the hospital and kept NPO for 48 hours. She was started on clear liquid diet which she tolerated well and her diet was advanced the following day. She was deemed stable for discharge on post-operative day five with no complications from her procedure. The patient was seen at two-week and four-week follow-up. She reported complete resolution of her previous symptoms. She was instructed to follow-up on an annual basis.

\section{Discussion}

LABG has been commonly performed in the US and Europe. Due to previous popularity, it is reasonable to presume that complications such as the one discussed will continue to increase in number. This case may be considered a late or delayed complication of LAGB, as this patient had the band in place for nine months before this episode occurred. A literature review revealed multiple reports of cecal volvulus and/or small bowel obstruction due to the connecting tube of the LAGB (see Table 1). These complications arose from 1.5 to 9 years after placement of the LAGB. ${ }^{[8-14]}$ Additionally, patients frequently report significant discomfort in the postoperative period and complain of reflux like symptoms and dysphagia. Fifty percent of patients questioned by Gustavsson with a standardized protocol two years postLAGB admitted to heartburn and acid regurgitation. Routine endoscopic surveillance revealed a prevalence of erosive esophagitis of $44 \%$. After a median follow-up of seven years, $58 \%$ of the patients had required reoperation usually with excision of the band system and conversion to Roux-En-Y gastric bypass. ${ }^{[15]}$

In this case, we de-torsed the cecum and shortened the tubing to prevent re-adhesion, but we did not perform a resection as all tissues appeared viable. We also did not perform a cecopexy. Current literature demonstrates that, while resection of the hypermobile colon segment prevents reoccurrence, it is associated with greater physiologic insult and morbidity in the post-operative period. Cecopexy has been associated with post-operative mortality of $0 \%-30 \%$ and recurrence rates as high as $40 \% .{ }^{[16]}$ We feel that our decision to leave the cecum intact and forego cecopexy was justified considering that the causative agent was addressed when the gastric band tubing was shortened and the causative adhesions were lysed.

Table 1. Additional documented cases of small bowel obstruction and cecal volvulus due to LAGB along with the length of time since LABG placement and the associated intervention due to the complication

\begin{tabular}{|c|c|c|c|}
\hline Author & Complication & $\begin{array}{l}\text { Time Since } \\
\text { LAGB Procedure }\end{array}$ & Intervention \\
\hline Hashemzadeh, et al. ${ }^{[8]}$ & $\begin{array}{l}\text { Small Bowel Obstruction with Perforations Due to } \\
\text { Connection Tubing }\end{array}$ & 1.5 Years & $\begin{array}{l}\text { Omental Patch on Perforations; Removal of } \\
\text { Gastric Band }\end{array}$ \\
\hline Fakhro, et al. ${ }^{[9]}$ & Cecal Volvulus Due to Connection Tubing & 2 Years & $\begin{array}{l}\text { Cecal Decompression, Appendectomy, and } \\
\text { Cecopexy }\end{array}$ \\
\hline Agahi and Harle ${ }^{[10]}$ & Cecal Volvulus Due to Connection Tubing & 2 Years & Cecectomy with End-to-End Anastomosis \\
\hline Zappa, et al. ${ }^{[1]]}$ & Small Bowel Obstruction Due to Connection Tube & 3 Years & Lysis of Adhesions \\
\hline $\begin{array}{l}\text { Shipman, Bohra, and } \\
\text { Labib }^{[12]}\end{array}$ & Cecal Volvulus Due to Connection Tubing & 4 Years & $\begin{array}{l}\text { Right Hemicolectomy with Ileocolic } \\
\text { Anastomosis }\end{array}$ \\
\hline Tan, et al. ${ }^{[13]}$ & $\begin{array}{l}\text { Small Bowel Obstruction; Colonic Erosion of } \\
\text { Connection Tubing }\end{array}$ & 5 Years & $\begin{array}{l}\text { Primary Repair of Colonic Perforation; } \\
\text { Omental Patch; Removal of Gastric Band }\end{array}$ \\
\hline $\begin{array}{l}\text { Shipkov, Uchikov, and } \\
\text { Uchikova }^{[14]}\end{array}$ & Small Bowel Obstruction Due to Connection Tube & 9 Years & $\begin{array}{l}\text { Bowel Resection with End Ileostomy; Later } \\
\text { Ileo-to-Ileo Anastomosis }\end{array}$ \\
\hline
\end{tabular}

\section{Conclusions}

Our case is a rare but reported complication of LAGB. It is one of a few known cases where a cecal volvulus occurred as a consequence of adhesions between the colon and the

Published by Sciedu Press gastric band tubing. There is little immediate morbidity and mortality associated with LAGB, but in the long term, the complication rate is relatively high. As a result, this case further supports the notion that there should be a higher clinical 
suspicion for possible cecal volvulus and/or bowel obstruction in patients presenting with abdominal pain following LAGB placement. Also, the addition of this case report to the current literature supports consideration for other bariatric procedures with lower long-term morbidity.

\section{Consent}

Consent from the patient for this case report was obtained.

\section{CONFlicts OF InTEREST Disclosure}

The authors declare they have no conflicts of interest.

\section{REFERENCES}

[1] Flegal KM, Carroll MD, Ogden CL, et al. Prevalence and Trends in Obesity Among US Adults, 1999-2000. JAMA. 2002; 288: 1728 32. PMid: 12365956. https://doi.org/10.1001/jama.288.1 4.1723

[2] Livingston EH, Ko CY. Socioeconomic Characteristics of the Population Eligible for Obesity Surgery. Surgery. 2004; 135: 288-296. PMid: 14976479. https://doi.org/10.1016/j.surg. 2003.07.008

[3] NIH Conference: Gastrointestinal Surgery for Severe Obesity - Consensus Development Conference Panel. Ann Intern Med. 1991; 115 956-61. https://doi.org/10.7326/0003-4819-115-12-956

[4] Terzi G, Aran G, Ozgurbuz U, et al. Anesthetic Management for Severe Morbid Obesity. The Internet Journal Of Anesthesiology. 2008; 16.

[5] Ballantyne M. Measuring Outcomes Following Bariatric Surgery: Weight Loss Parameters, Improvement in Co-Morbid Conditions, Change in Quality of Life and Patient Satisfaction. Obesity Surgery. 2003; 13: 954-964. PMid: 14738691. https ://doi.org/10.138 1/096089203322618867

[6] Susmallian S, Ezri T, Elis M, et al. Access-Port Complications After Laparoscopic Gastric Banding. Obesity Surgery. 2003; 13: 128131. PMid: 12630627 . https://doi.org/10.1381/0960892033 21136728

[7] Niville E, Dams A, Vlasselaers J. Lap Band Erosion: Incidence and Treatment. Obesity Surgery. 2001; 11: 744-747. PMid: 11775574. https://doi.org/10.1381/09608920160558704

[8] Hashemzadeh M, KaramiRad M, Zahedi-Shoolami L. Laparoscopic Adjustable Gastric Banding Connecting Tube Causing Small Bowel Obstruction and Perforation. Case Reports in Surgery. 2013; 1-3. PMid: 24368962. https://doi .org/10.1155/2013/296037
[9] Zappa MA, Lattuada E, Mozzi E. An Unusual Complication of Gastric Banding: Recurrent Small Bowel Obstruction Caused by the Connecting Tube. Obesity Surgery. 2006; 16: 939-941. PMid: 16839499. https://doi .org/10.1381/096089206777822250

[10] Tan L, So J, Shabbir A. Connection Tubing Causing Small Bowel Obstruction and Colonic Erosion As A Rare Complication After Laparoscopic Gastric Banding: A Case Report. J Medical Case Reports. 2012; 6(9): 1-3. https://doi .org/10.1186/1752-1947-6-9

[11] Shipkov CD, Uchikov AP, Uchikova EH. Small Bowel Obstruction by the Silicone Tube of the Gastric Band. Obesity Surgery. 2006; 16: 829-835.

[12] Fakhro A, O'Riordan JM, Lawler LP, et al. Cecal Volvulus as a Complication of Gastric Banding. Obesity Surgery. 2009; 19: 17341736. PMid: 18830781. https://doi.org/10.1007/s11695-0 08-9703-8

[13] Agahi A, Harle R. A Serious But Rare Complication of Laparoscopic Adjustable Gastric Banding: Bowel Obstruction Due to Cecal Volvulus. Obesity Surgery. 2009; 19: 1197-1200. PMid: 19437083 https://doi.org/10.1007/s11695-009-9847-1

[14] Shipman K, Bohra A, Labib M. Caecal Volvulus As A Rare Complication of Laparoscopic Adjustable Gastric Banding. J Surg Case Reports. 2012; 10(5): 1-3. https://doi.org/10.1093/jscr/2 012.10 .5

[15] Gustavsson S, Westling A. Laparoscopic Adjustable Gastric Banding: Complications and Side Effects Responsible for the Poor Long-Term Outcome. Semin Laparosc Surg. 2002; 9: 115-124. PMid: 12152154 https://doi.org/10.1053/slas.2002.126328

[16] Consorti ET, Liu TH. Diagnosis and Treatment of Caecal Volvulus. Postgrad Med J. 2005; 81: 772-77. PMid: 16344301. https: //doi.org/10.1136/pgmj.2005.035311 